\title{
Anthropometric correlation with hamstring graft size in anterior cruciate ligament reconstruction among males
}

\author{
Isam Moghamis ${ }^{1}$ - Yousef Abuodeh ${ }^{1} \cdot$ Ali Darwiche $^{1} \cdot$ Talal Ibrahim $^{2} \cdot$ Mohammad Al Ateeq Al Dosari $^{1}$. \\ Ghalib Ahmed ${ }^{1,3}$ (I)
}

Received: 5 September 2019 / Accepted: 11 November 2019 /Published online: 26 December 2019

(C) The Author(s) 2019

\begin{abstract}
Purpose Pre-operative knowledge of hamstring graft size for anterior cruciate ligament reconstruction (ACL) is of clinical importance and useful in making appropriate decisions about graft choice. This study investigated if there is any correlation between anthropometric measurements such as height, weight, body mass index, thigh length, and circumference with the size of hamstring tendon graft in anterior cruciate ligament reconstruction.

Methods The anthropometric data of 50 consecutive adult males, who underwent primary ACL reconstruction using quadruple hamstring autograft, were collected prospectively. Data analysis using Pearson's correlation test was performed and multiple logistic regression analysis was used to investigate any correlation not detected by Pearson's test and to eliminate confounders. Results Patient's height and thigh length demonstrated a positive correlation with gracilis graft length $(r=.464, P=.001$, $r=.456, P=.001$, respectively) and semitendinosus graft length $(r=.541, P=000, r=.578, P=.000$, respectively). While the patient's age was the only independent factor which had a positive correlation with the quadrupled hamstring graft diameter $(r=.412, P=.004)$, multiple regression analysis showed abdominal girth had a significant negative correlation with gracilis $(P=.04)$ and semitendinosus $(P=.006)$ graft thickness.

Conclusion This study demonstrated that some anthropometric measurements had a positive correlation with the hamstring graft length and diameter in male patients. Hence, these results provide preliminary support for the use of some anthropometric measurements in the preoperative planning and prediction of the hamstring graft length and diameter in anterior cruciate ligament reconstruction.
\end{abstract}

Keywords Anterior cruciate ligament $\cdot$ Hamstring graft size $\cdot$ Anthropometric measurements

\section{Introduction}

Rupture of the anterior cruciate ligament (ACL) is one of the most common encountered knee injuries [1]. Deficiency of this ligament can be severely detrimental to high-level athletes or individuals participating in sports [2].

The aim of an ACL reconstruction is to restore the function and biomechanics of the native ligament. Various grafts available for use in the reconstruction of the ACL and the

Ghalib Ahmed

ghaliboudah@gmail.com; gahmed@hamad.qa

1 Orthopedics Department, Hamad General Hospital, Hamad Medical Corporation, PO Box 3050, Doha, Qatar

2 Pediatric Orthopedic, SIDRA Hospital, Doha, Qatar

3 Weil Cornell Medical College, Ar-Rayyan, Qatar hamstring is one of the most commonly utilized autograft [3, 4]. A graft diameter greater than $8 \mathrm{~mm}$ has been recommended by many authors in order to reduce the risk of graft failure [5-7]. There are considerable variations in the size of hamstring tendons between individuals, and hence graft diameter is often unpredictable.

Pre-operative knowledge of the hamstring graft length and diameter is of clinical importance and may assist surgeons in making appropriate and informed decisions about the graft choices which may increase surgeon's confidence and enhance patient's evaluation and counseling regarding graft choice [8-10].

Various studies exist in the literature regarding prediction of graft size. However, no consensus has been reached due to differences in results between the studies [11-13].

This study investigated if there is any correlation between anthropometric measurements such as height, weight, body mass index, thigh length, and thigh circumference with the 
size of hamstring tendon graft in anterior cruciate ligament (ACL) reconstruction.

We hypothesized that there is no correlation between some anthropometric measurements with the size of the hamstring tendon graft that is used in anterior cruciate ligament reconstruction among males.

\section{Material and methods}

We prospectively collected anthropometric data of 50 consecutive patients with ACL deficiency confirmed by MRI studies pre-operatively and scheduled to undergo primary arthroscopic ACL reconstruction using a single-bundle quadruple hamstring tendon autograft, between September 2014 and January 2017. Approval for the study was obtained from our Institutional Review Board.

All adult male patients with isolated ACL deficiency undergoing primary arthroscopic ACL reconstruction using a hamstring tendon autograft were included in this study. Female patients, children under the age of 18 years, patients who had undergone previous ACL reconstruction, multiple ligamentous injuries, patients treated using grafts other than hamstring, doublebundle hamstring graft reconstructions, single-bundle hamstring graft reconstruction, and patients with neuromuscular diseases were excluded from the study.

Informed consent was obtained from all patients prior to their inclusion. The following data was collected from patients: age, ethnicity, height, weight, abdominal girth, thigh length, and thigh circumference. The abdominal girth, thigh length, and thigh circumference measurements were taken while the patients were supine and knees in full extension.

Abdominal girth was measured by placing the tape around the abdomen at the level of the umbilicus. Thigh length was measured from the anterior superior iliac spine (ASIS) to the superolateral border of the patella. The thigh circumference was measured at a point $15 \mathrm{~cm}$ proximal to the superolateral border of the patella.

Two senior board certified fellowship trained knee surgeons performed all operations using the same harvesting technique. Using a skin incision distal to the insertion of the tendons on the proximal tibia, both semitendinosus and gracillis tendons were harvested by a closed graft harvester. Graft length was determined from the tibia insertion including the pretibial periosteum to the tendon tail while tendon length was from the tibia insertion including the pretibial periosteum to the tendomuscular junction. Intraoperative measurements of each tendon were recorded by the operating surgeons after removal of the fat and muscle tissue attached to each tendon.
Fig. 1 a Graft thickness measurement. b Graft width measurements. c Tendon length (black arrow) and graft length (red arrow) measurements

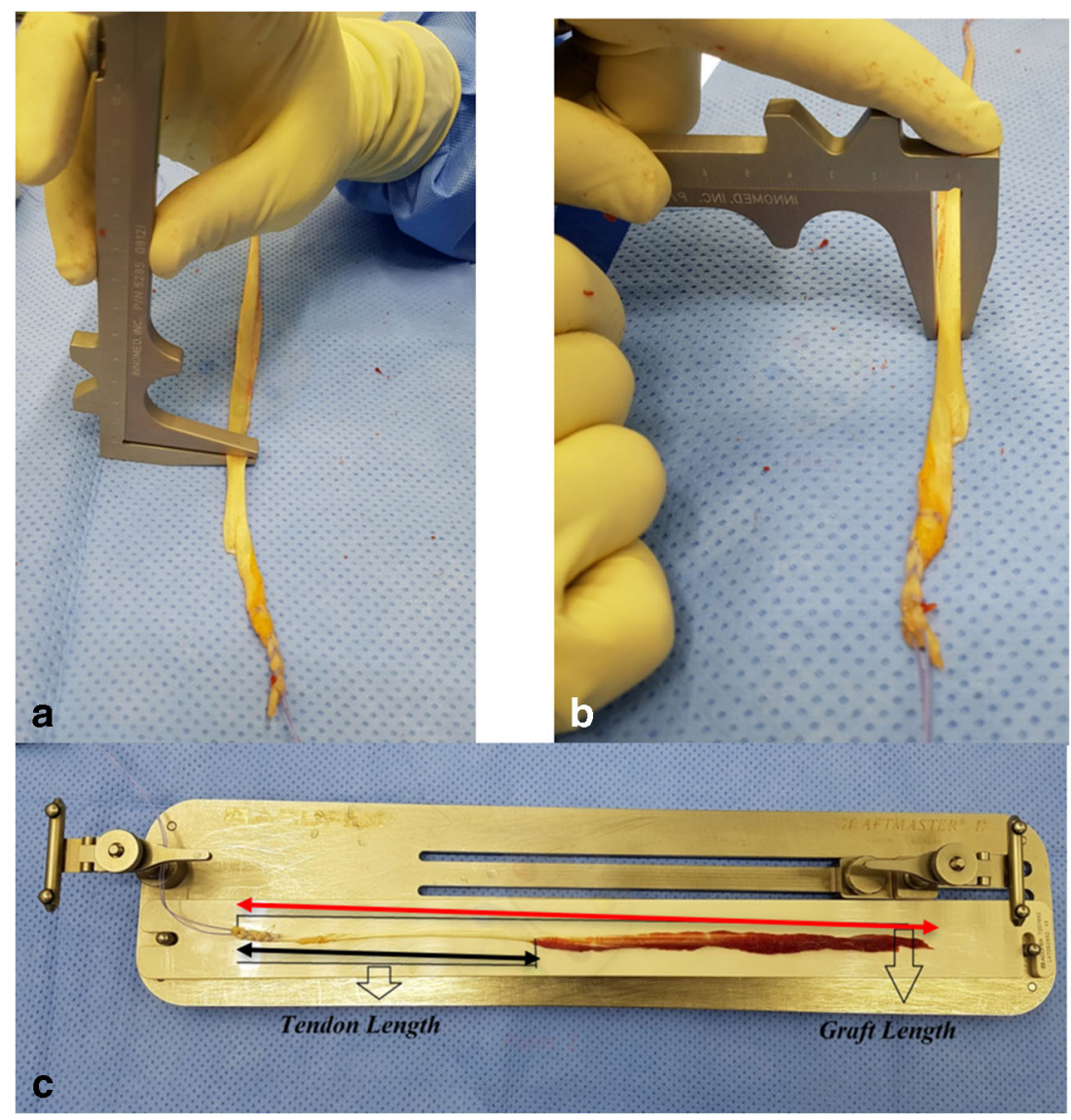


The measurements included length of the full graft, length of tendon, its width, and thickness of the tendons in millimeters (Fig. 1).

The hamstring graft was prepared using a single-bundle 4strand technique with each end of the tendon whip stitched using the same non-absorbable size 2 ethibond suture. The final graft diameter was measured using the ACL reconstruction graft diameter measurement guide (Smith and Nephew, Androver, USA) and the diameter was defined as the smallest calibrated size in which the graft could pass through (Fig. 2).

\section{Data analysis}

IBM SBSS Statistics (version 24) software was used for statistical analysis. Pearson's test was used to identify correlations between anthropometric measurements and graft dimension. For results with positive correlation, simple linear regression analysis was used to estimate the linear curves. Multiple logistic regression analysis was used to investigate correlations not detected by Pearson's test and to eliminate confounders. The positive results were considered statistically significant if the $P$ value was less than $5 \%(P \leq .05)$.

\section{Results}

A total number of 50 consecutive male patients agreed to participate in the study. There were 3 patients who had missing data of the final graft diameter. Table 1 presents the means of patient's demographics along with the mean of the anthropometric measurement taken.

The mean length of the harvested gracilis tendons was $147.3 \mathrm{~mm}( \pm 37.1 \mathrm{SD})$. Whereas, the mean graft length was $273.9 \mathrm{~mm}( \pm 33.1 \mathrm{SD})$ with mean width of $4.7 \mathrm{~mm}( \pm 2.1 \mathrm{SD})$ and mean thickness of $1.8 \mathrm{~mm}( \pm .8 \mathrm{SD})$. On the other hand,

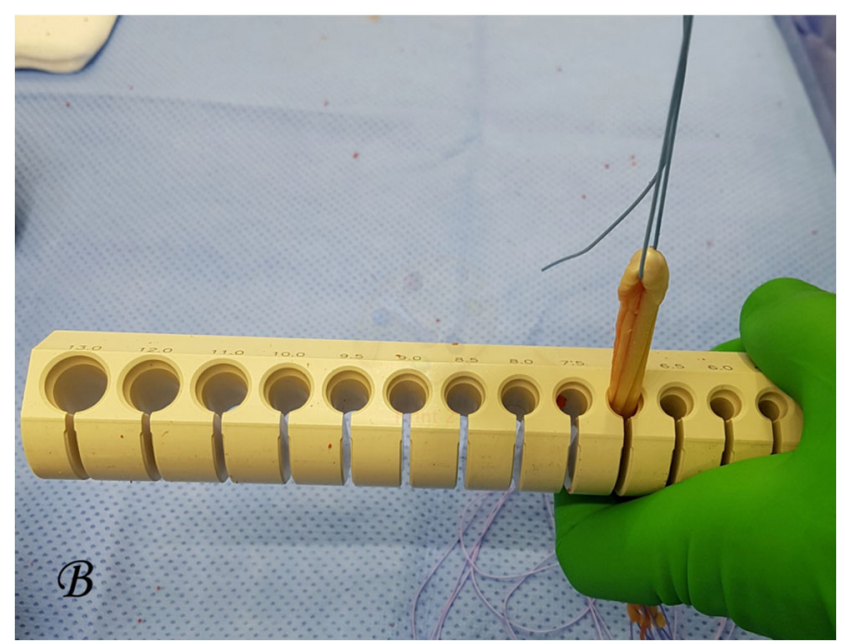

Fig. 2 Hamstring graft diameter measurement using a diameter measurement tool (Smith and Nephew, Androver, USA)
Table 1 Patients' characteristics

\begin{tabular}{|c|c|c|}
\hline & Mean & $\mathrm{SD}$ \\
\hline Age (year) & 29 & 7 \\
\hline Weight (kg) & 82.2 & 11.2 \\
\hline Height (cm) & 174 & 8 \\
\hline BMI & 27.0 & 3.5 \\
\hline Abdominal girth $(\mathrm{cm})$ & 86.80 & 8.734 \\
\hline Thigh length $(\mathrm{cm})$ & 46.64 & 2.701 \\
\hline Thigh circumference $(\mathrm{cm})$ & 50.74 & 3.784 \\
\hline Surgery side & $N$ & $\%$ \\
\hline Left & 23 & 46.0 \\
\hline Right & 27 & 54.0 \\
\hline Measurement side & $N$ & $\%$ \\
\hline Left & 26 & 52.0 \\
\hline Right & 24 & 48.0 \\
\hline Ethnicity & $N$ & $\%$ \\
\hline African & 17 & 34.0 \\
\hline Asia & 17 & 34.0 \\
\hline Middle East & 14 & 28.0 \\
\hline European & 2 & 4.0 \\
\hline
\end{tabular}

the mean length of harvested Semitendinosus tendons was $172.1 \mathrm{~mm}( \pm 38.9 \mathrm{SD})$ and the mean graft length was $307.5 \mathrm{~mm}( \pm 31.9 \mathrm{SD})$ with a mean width of $6.0 \mathrm{~mm}( \pm 2.8$ $\mathrm{SD})$ and a mean thickness of $2.3 \mathrm{~mm}( \pm .98 \mathrm{SD})$. The whole, single bundle 4-strands, mean graft diameter was $7.3 \mathrm{~mm}$ ( $\pm .67 \mathrm{SD})$ (Table 2).

Analysis of correlation among results showed that patient's height demonstrated a significant positive moderate correlation with gracilis graft length $(r=.464, P=.001)$ and semitendinosus graft length $(r=.541, P=.000)$. In addition, it showed a weak significant positive correlation with semitendinosus tendon length $(r=.337, P=.017)$ (Table 3$)$.

Table 2 Graft measurement outcome

\begin{tabular}{lllllll}
\hline & Parameters & $N$ & Min. & Max & Mean & SD \\
\hline Gracilis & $\begin{array}{c}\text { Tendon length } \\
\text { (mm) }\end{array}$ & 50 & 100 & 270 & 147.30 & 37.146 \\
& Graft length (mm) & 50 & 180 & 350 & 273.90 & 33.094 \\
& Width (mm) & 50 & 2.0 & 10.0 & 4.730 & 2.1122 \\
& Thickness (mm) & 50 & .8 & 5.0 & 1.766 & .7883 \\
Semitendinosus & Tendon length & 50 & 100 & 340 & 171.00 & 38.914 \\
& $\quad$ (mm) & & & & & \\
& Graft length (mm) & 50 & 240 & 370 & 307.50 & 31.916 \\
& Width (mm) & 50 & 2.0 & 15.0 & 6.020 & 2.7811 \\
& Thickness (mm) & 50 & 1.0 & 4.0 & 2.266 & .9884 \\
ACL hamstring graft diameter (mm) & 47 & 6.0 & 9.0 & 7.266 & .6745 \\
\hline
\end{tabular}


Table 3 Correlation coefficient between intraoperative measurement and anthropometric data

Gracilis

\begin{tabular}{|c|c|c|c|c|c|c|c|c|}
\hline & Tendon length & & Graft length & Width & & Thickness & & \\
\hline & $\begin{array}{l}\text { Correlation } \\
\text { coefficient }\end{array}$ & $P$ value & $\begin{array}{l}\text { Correlation } \\
\text { coefficient }\end{array}$ & $P$ value & $\begin{array}{l}\text { Correlation } \\
\text { coefficient }\end{array}$ & $P$ value & $\begin{array}{l}\text { Correlation } \\
\text { coefficient }\end{array}$ & $P$ value \\
\hline Age & -.054 & .710 & .165 & .252 & .012 & .932 & -.054 & .708 \\
\hline Weight & -.022 & .880 & .274 & .054 & -.090 & .533 & .044 & .759 \\
\hline Height & .192 & .181 & .464 & .001 & -.104 & .474 & .010 & .944 \\
\hline BMI & -.141 & .329 & -.025 & .862 & -.037 & .799 & .043 & .769 \\
\hline Abdominal girth & .127 & .380 & .072 & .618 & -.002 & .990 & -.112 & .438 \\
\hline Thigh length & .187 & .192 & .456 & .001 & -.025 & .866 & .066 & .649 \\
\hline Thigh circumference & -.148 & .305 & -.136 & .346 & -.144 & .317 & .239 & .094 \\
\hline \multicolumn{9}{|l|}{ Semitendinosus } \\
\hline & Tendon length & & Graft length & Width & & Thickness & & \\
\hline & $\begin{array}{l}\text { Correlation } \\
\text { coefficient }\end{array}$ & $P$ value & $\begin{array}{l}\text { Correlation } \\
\text { coefficient }\end{array}$ & $P$ value & $\begin{array}{l}\text { Correlation } \\
\text { coefficient }\end{array}$ & $P$ value & $\begin{array}{l}\text { Correlation } \\
\text { coefficient }\end{array}$ & $P$ value \\
\hline Age & .089 & .539 & .139 & .334 & .070 & .631 & .051 & .727 \\
\hline Weight & .113 & .437 & .258 & .070 & -.129 & .371 & .115 & .426 \\
\hline Height & .337 & .017 & .541 & .000 & -.013 & .928 & .097 & .503 \\
\hline BMI & -.094 & .517 & -.093 & .520 & -.140 & .333 & .057 & .694 \\
\hline Abdominal girth & .104 & .472 & -.090 & .532 & .005 & .971 & -.135 & .350 \\
\hline Thigh length & .217 & .130 & .578 & .000 & -.091 & .528 & .238 & .097 \\
\hline Thigh circumference & -.093 & .520 & -.203 & .157 & -.240 & .093 & .106 & .463 \\
\hline \multicolumn{9}{|c|}{ ACL hamstring graft diameter } \\
\hline & $\begin{array}{l}\text { Correlation } \\
\text { coefficient }\end{array}$ & $P$ value & & & & & & \\
\hline Age & .412 & .004 & & & & & & \\
\hline Weight & .166 & .265 & & & & & & \\
\hline Height & .194 & .192 & & & & & & \\
\hline BMI & .046 & .757 & & & & & & \\
\hline Abdominal girth & .051 & .732 & & & & & & \\
\hline Thigh length & .116 & .437 & & & & & & \\
\hline Thigh circumference & -.073 & .624 & & & & & & \\
\hline
\end{tabular}

Thigh length was found to have a significant positive moderate correlation with gracilis graft length $(r=.456, P=.001)$ and semitendinosus graft length $(r=.578, P=.000)$.

Furthermore, patient age demonstrated a significant positive moderate correlation with the final graft diameter ( $r=.412, P=.004)$. There was no statistically significant correlation between hamstring graft diameter and the remaining anthropometric measurements.

Simple linear regression analysis results for estimated curves showed that gracilis graft length measurement variation could be explained by patient's height and thigh length $\left(R^{2}=.215, P=.001\right.$ and $R^{2}=.207$, $P=.001$, respectively). Semitendinosus graft length measurement variations could also be explained by patient's height and thigh length $\left(R^{2}=.292, P=.000\right.$ and $R^{2}=.334, P=.000$, respectively). Semitendinosus tendon length measurement variations were explained by height $\left(R^{2}=.114, P=.017\right)$. Variations of final hamstring graft diameter could be explained by age $\left(R^{2}=.170, P=.004\right)$ (Table 4, Fig. 3).

Multiple regression analysis demonstrated a significant positive correlation between abdominal girth and gracilis tendon length $(P=.003)$ but not significant for semitendinosus tendon length $(P=.143)$, a significant negative correlation between abdominal girth and gracilis graft thickness

Table 4 Results of simple linear regression analysis

\begin{tabular}{llll}
\hline Dependent & Independent & $R^{2}$ & $P$ value \\
\hline Gracilis graft length & Height & .215 & .001 \\
& Thigh length & .207 & .001 \\
Semitendinosus graft length & Height & .292 & .000 \\
& Thigh length & .334 & .000 \\
Semitendinosus tendon length & Height & .114 & .017 \\
ACL hamstring graft diameter & Age & .170 & .004 \\
\hline
\end{tabular}


a Gracilis Graft Length $(\mathrm{mm})$ Vs Thigh Length $(\mathrm{cm})$

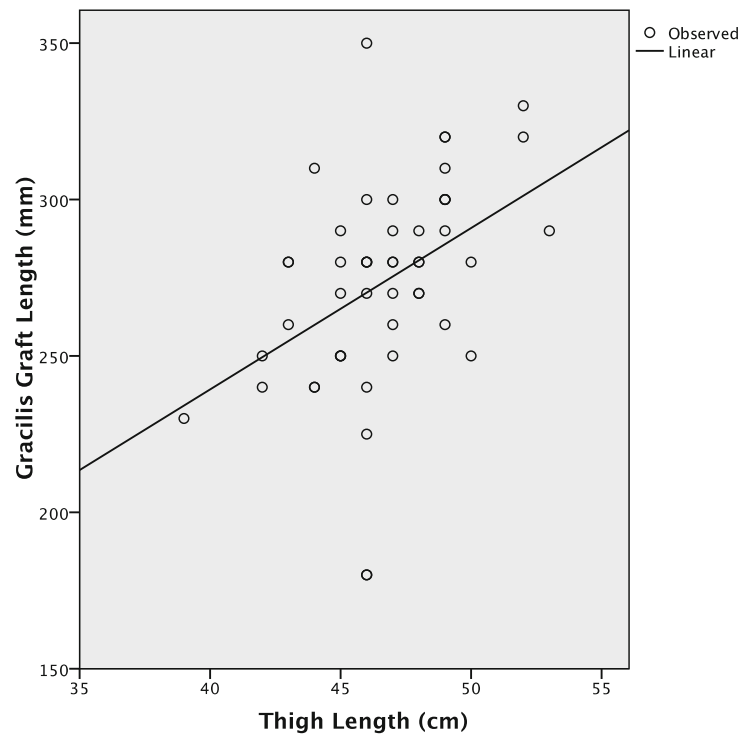

c Semitendinosus Graft Length $(\mathrm{mm})$ Vs Thigh Length $(\mathrm{cm})$

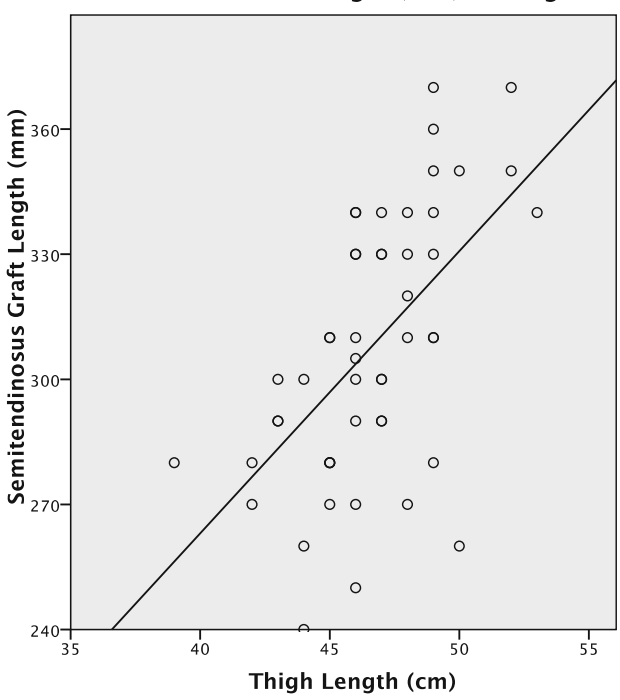

e Semitendinosus Tendon Length $(\mathrm{mm})$ Vs Height $(\mathrm{cm})$

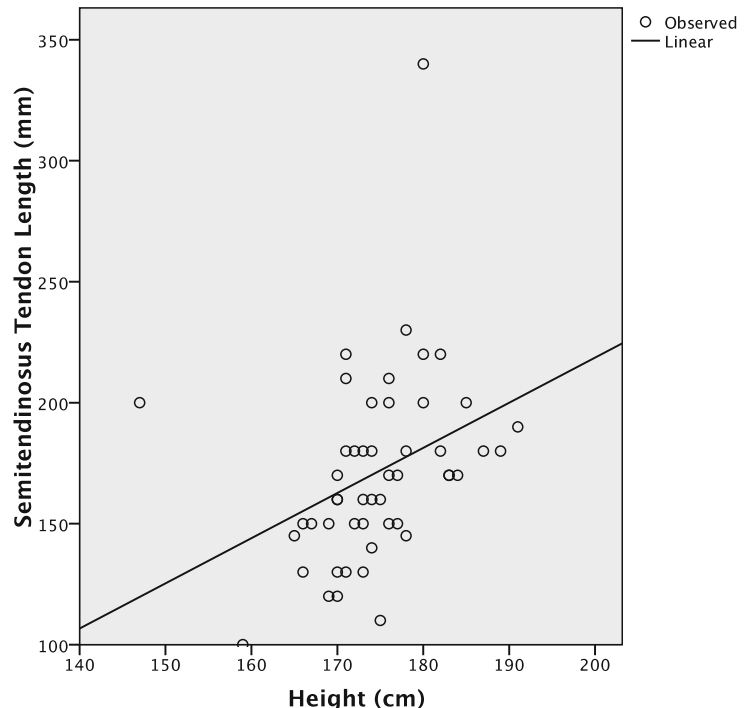

b Gracilis Graft Length $(\mathrm{mm})$ Vs Height $(\mathrm{cm})$

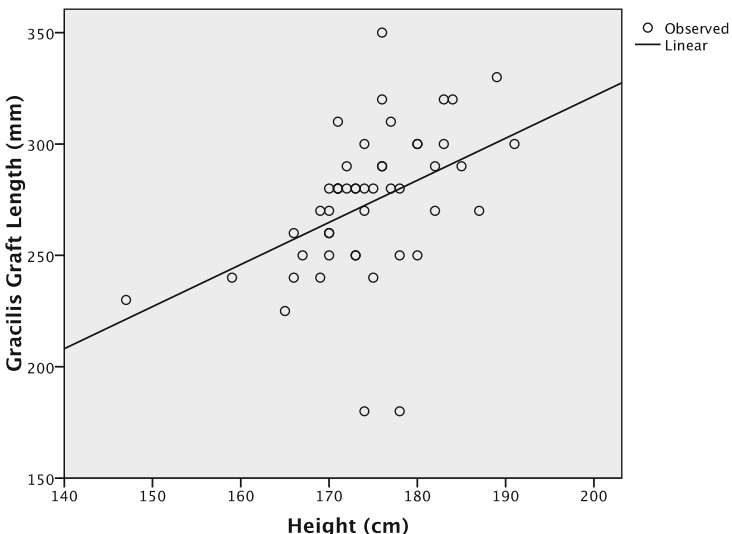

d Semitendinosus Graft Length $(\mathrm{mm})$ Vs Height $(\mathrm{cm})$
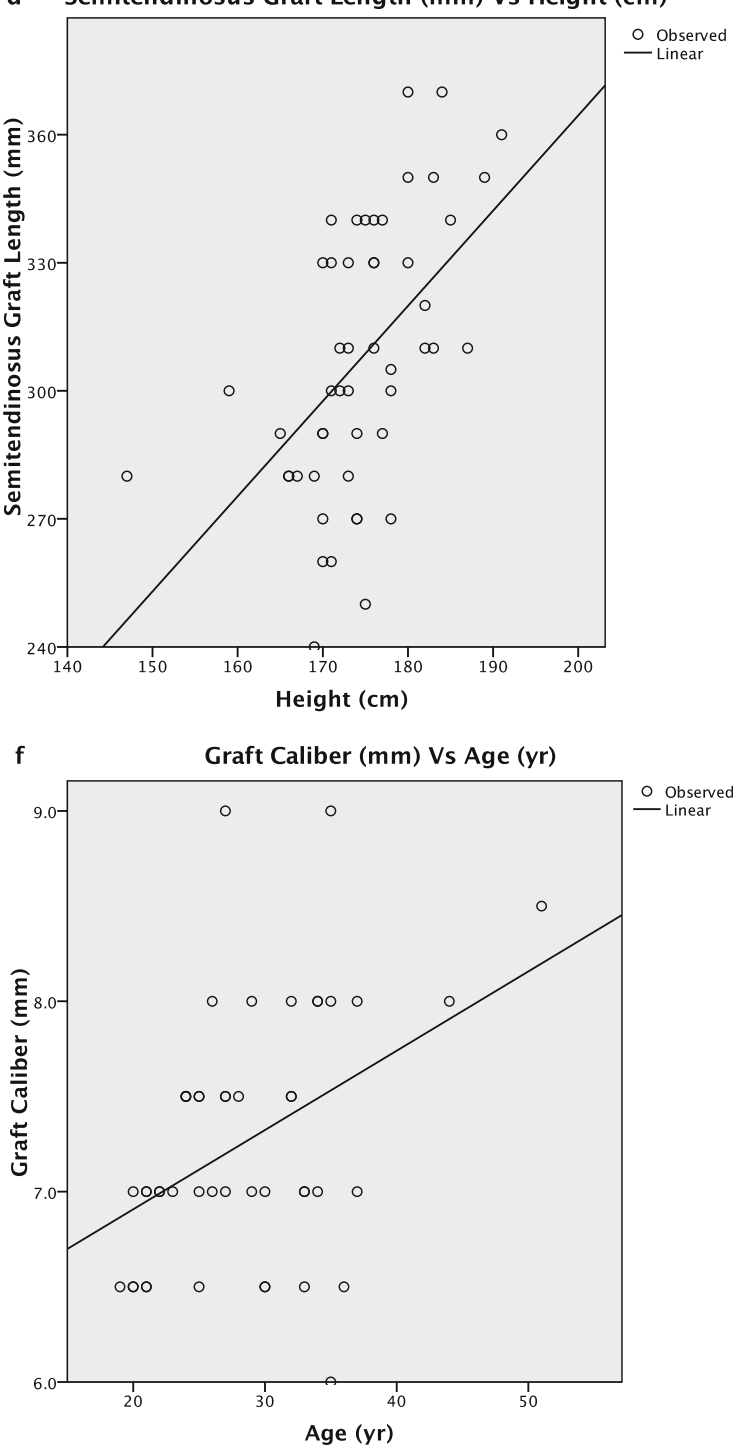

Fig. 3 Curve estimates by simple linear regression ( $R$-squared values in Table 4) 
$(P=.040)$ and semitendinosus graft thickness $(P=.006)$ and a significant positive correlation between the thigh circumference and gracilis graft thickness $(P=.019)$ but not significant for semitendinosus graft thickness $(P=.262)$, whereas thigh length had a significant positive correlation on only semitendinosus graft length $(P=.016)$. The age was found to have a significant positive effect on the final ACL hamstring graft diameter $(P=.013)$ (Table 5). Finally, the number of patients in the different ethnic groups was small and any statistical analysis would be misleading.

\section{Discussion}

The ability to predict the length of the hamstring graft preoperatively is of great importance and may help the surgeon in the decision to achieve an acceptable diameter for the autograft in ACL reconstruction.

This study demonstrated a positive correlation between the patient height and thigh length with semitendinosus and gracilis graft length; this positive correlation was also reported in previous literatures [14-17].

In addition, we could not find a positive correlation between height and the final graft diameter; however, several studies have demonstrated such positive correlation among females [11-13, 18, 19]. In another study of 89 Asian males who underwent primary ACL reconstruction with quadrupled hamstring autograft also were unable to show this correlation [20].

Furthermore, we found no correlation between BMI and the final graft diameter in males as the females were excluded in our study. In previous studies, one author reported that BMI was correlated to the graft diameter in females but not in male

Table 5 Results of multiple regression analysis

\begin{tabular}{|c|c|c|c|c|c|c|c|c|}
\hline & Gracilis & & & & & & & \\
\hline & Tendon length & & Graft length & & Width & & Thickness & \\
\hline & Coefficient & $P$ value & Coefficient & $P$ value & Coefficient & $P$ value & Coefficient & $P$ value \\
\hline Constant & -.923 & .362 & -.028 & .978 & 1.442 & .157 & -.532 & .598 \\
\hline Age & -.625 & .535 & .943 & .351 & -.211 & .834 & .731 & .469 \\
\hline Weight & -1.017 & .315 & .064 & .949 & 1.215 & .231 & -.420 & .677 \\
\hline Height & .940 & .353 & .166 & .869 & -1.344 & .186 & .445 & .658 \\
\hline BMI & .650 & .519 & .021 & .984 & -1.200 & .237 & .435 & .666 \\
\hline Abdominal girth & 3.121 & .003 & .086 & .932 & .807 & .424 & -2.121 & .040 \\
\hline Thigh length & .822 & .416 & 1.562 & .126 & .406 & .687 & .587 & .560 \\
\hline \multirow[t]{4}{*}{ Thigh circumference } & -.597 & .554 & -.888 & .380 & -1.160 & .253 & 2.431 & .019 \\
\hline & \multicolumn{8}{|l|}{ Semitendinosus } \\
\hline & \multicolumn{2}{|l|}{ Tendon length } & \multicolumn{2}{|l|}{ Graft length } & \multicolumn{2}{|l|}{ Width } & \multicolumn{2}{|l|}{ Thickness } \\
\hline & Coefficient & $P$ value & Coefficient & $P$ value & Coefficient & $P$ value & Coefficient & $P$ value \\
\hline Constant & -1.545 & .130 & -.236 & .815 & 1.722 & .092 & -.491 & .626 \\
\hline Age & .517 & .608 & 1.381 & .174 & .166 & .869 & 1.151 & .256 \\
\hline Weight & -1.467 & .150 & -.122 & .904 & 1.496 & .142 & -.355 & .724 \\
\hline Height & 1.614 & .114 & .447 & .657 & -1.526 & .135 & .386 & .701 \\
\hline BMI & 1.236 & .223 & .404 & .688 & -1.627 & .111 & .575 & .568 \\
\hline Abdominal girth & 1.493 & .143 & -1.873 & .068 & 1.786 & .081 & -2.882 & .006 \\
\hline Thigh length & .169 & .867 & 2.499 & .016 & -.566 & .574 & 1.601 & .117 \\
\hline \multirow[t]{2}{*}{ Thigh circumference } & -.025 & .981 & -1.099 & .278 & -1.278 & .208 & 1.138 & .262 \\
\hline & \multicolumn{8}{|c|}{ ACL hamstring graft diameter } \\
\hline Constant & $\begin{array}{r}\text { Coefficient } \\
.165\end{array}$ & $\begin{array}{r}P \text { value } \\
.870\end{array}$ & & & & & & \\
\hline Age & 2.606 & .013 & & & & & & \\
\hline Weight & -.003 & .998 & & & & & & \\
\hline Height & .141 & .889 & & & & & & \\
\hline BMI & .077 & .939 & & & & & & \\
\hline Abdominal girth & -.818 & .418 & & & & & & \\
\hline Thigh length & .270 & .788 & & & & & & \\
\hline Thigh circumference & -.120 & .905 & & & & & & \\
\hline
\end{tabular}


[21], another author showed no correlation with BMI in both genders [11], and few authors had shown only a weak positive correlation between BMI and the quadrupled hamstring graft diameter [21, 22].

It is interesting to note that, in our study, the patient age was the only independent variable that had a positive correlation with the final graft diameter. The previous studies had demonstrated a negative correlation with age as a predictor of final quadrupled hamstring graft diameter [12, 13, 23].

Additionally, we were able to find a significant negative correlation between abdominal girth with gracilis and semitendinosus thickness as well as a significant positive correlation between thigh circumference and only gracilis thickness, which were not reported in previous literatures.

Some of the limitations of our study include small sample size, exclusion of females, the measurement technique is challenging and may be inaccurate for a thin tendon with varying width and thickness along the length and having two different surgeons involved in graft harvesting and measurement, possibility of other confounding factor and statistical artifacts to add more, and variability of amount of tension applied on the graft during sizing has an effect on the final graft caliber measurements intra-operatively.

\section{Conclusion}

This study demonstrated that some anthropometric measurements had a positive correlation with the hamstring graft length and diameter in male patients. Hence, these results provide preliminary support for the use of some anthropometric measurements in the preoperative planning and prediction of the hamstring graft length and diameter in anterior cruciate ligament reconstruction.

Funding Information Open Access funding provided by the Qatar National Library.

\section{Compliance with ethical standards}

Conflict of interest The authors declare that they have no conflict of interest.

Ethical approval Approval for the study was obtained from our Institutional Review Board.

Open Access This article is distributed under the terms of the Creative Commons Attribution 4.0 International License (http:// creativecommons.org/licenses/by/4.0/), which permits unrestricted use, distribution, and reproduction in any medium, provided you give appropriate credit to the original author(s) and the source, provide a link to the Creative Commons license, and indicate if changes were made.

\section{References}

1. Kaeding CC, Léger-St-Jean B, Magnussen RA (2017) Epidemiology and diagnosis of anterior cruciate ligament injuries. Clin Sports Med 36:1-8. https://doi.org/10.1016/j.csm.2016.08. 001

2. Papastergiou SG, Stergios PG, Konstantinidis GA et al (2012) Adequacy of semitendinosus tendon alone for anterior cruciate ligament reconstruction graft and prediction of hamstring graft size by evaluating simple anthropometric parameters. Anat Res Int 2012: 424158. https://doi.org/10.1155/2012/424158

3. Mahmoud SSS, Odak S, Coogan S, McNicholas MJ (2014) A prospective study to assess the outcomes of revision anterior cruciate ligament reconstruction. Int Orthop 38:1489-1494. https://doi. org/10.1007/s00264-014-2324-z

4. Romanini E, D'Angelo F, De Masi S et al (2010) Graft selection in arthroscopic anterior cruciate ligament reconstruction. J Orthop Traumatol 11:211-219. https://doi.org/10.1007/s10195-010-01249

5. Conte EJ, Hyatt AE, Gatt CJ, Dhawan A (2014) Hamstring autograft size can be predicted and is a potential risk factor for anterior cruciate ligament reconstruction failure. Arthroscopy 30:882-890. https://doi.org/10.1016/j.arthro.2014.03.028

6. Magnussen RA, Lawrence JTR, West RL et al (2012) Graft size and patient age are predictors of early revision after anterior cruciate ligament reconstruction with hamstring autograft. Arthroscopy 28: 526-531. https://doi.org/10.1016/j.arthro.2011.11.024

7. Mariscalco MW, Flanigan DC, Mitchell J et al (2013) The influence of hamstring autograft size on patient-reported outcomes and risk of revision after anterior cruciate ligament reconstruction: a Multicenter Orthopaedic Outcomes Network (MOON) Cohort Study. Arthroscopy 29:1948-1953. https://doi.org/10.1016/j. arthro.2013.08.025

8. Kautzner J, Kos P, Hanus M et al (2015) A comparison of ACL reconstruction using patellar tendon versus hamstring autograft in female patients: a prospective randomised study. Int Orthop 39: 125-130. https://doi.org/10.1007/s00264-014-2495-7

9. Lorenz S, Ahrens P, Kirchhoff S et al (2015) Dynamic quantification of tibio-femoral rotation in postero-lateral bundle insufficiency of the anterior cruciate ligament: a cadaver study. Int Orthop 39: 865-870. https://doi.org/10.1007/s00264-014-2537-1

10. Maeda A, Shino K, Horibe S et al (1996) Anterior cruciate ligament reconstruction with multistranded autogenous semitendinosus tendon. Am J Sports Med 24:504-509. https://doi.org/10.1177/ 036354659602400416

11. Pereira RN, Karam FC, Schwanke RL et al (2016) Correlation between anthropometric data and length and thickness of the tendons of the semitendinosus and gracilis muscles used for grafts in reconstruction of the anterior cruciate ligament. Rev Bras Ortop 51: 175-180. https://doi.org/10.1016/j.rboe.2016.01.011

12. Treme G, Diduch DR, Billante MJ et al (2008) Hamstring graft size prediction: a prospective clinical evaluation. Am J Sports Med 36: 2204-2209. https://doi.org/10.1177/0363546508319901

13. Tuman JM, Diduch DR, Rubino LJ et al (2007) Predictors for hamstring graft diameter in anterior cruciate ligament reconstruction. Am J Sports Med 35:1945-1949. https://doi.org/10.1177/ 0363546507304667

14. Challa S, Satyaprasad J (2013) Hamstring graft size and anthropometry in south Indian population. J Clin Orthop Trauma 4:135138. https://doi.org/10.1016/j.jcot.2013.09.005

15. Chiang E-R, Ma H-L, Wang S-T et al (2012) Hamstring graft sizes differ between Chinese and Caucasians. Knee Surg Sports Traumatol Arthrosc 20:916-921. https://doi.org/10.1007/s00167011-1653-3 
16. Goyal S, Matias N, Pandey V, Acharya K (2016) Are pre-operative anthropometric parameters helpful in predicting length and thickness of quadrupled hamstring graft for ACL reconstruction in adults? A prospective study and literature review. Int Orthop 40: 173-181. https://doi.org/10.1007/s00264-015-2818-3

17. Janssen RPA, van der Velden MJF, van den Besselaar M, Reijman M (2017) Prediction of length and diameter of hamstring tendon autografts for knee ligament surgery in Caucasians. Knee Surg Sports Traumatol Arthrosc 25:1199-1204. https://doi.org/10.1007/ s00167-015-3678-5

18. Pinheiro LFB, de Andrade MAP, Teixeira LEM et al (2011) Intraoperative four-stranded hamstring tendon graft diameter evaluation. Knee Surg Sports Traumatol Arthrosc 19:811-815. https://doi.org/ $10.1007 / \mathrm{s} 00167-010-1387-7$

19. Xie G, Huangfu X, Zhao J (2012) Prediction of the graft size of 4stranded semitendinosus tendon and 4-stranded gracilis tendon for anterior cruciate ligament reconstruction: a Chinese Han patient study. Am J Sports Med 40:1161-1166. https://doi.org/10.1177/ 0363546511435627
20. Loo W, Liu B, Lee Y, Soon Y (2010) Can we predict ACL hamstring graft sizes in the Asian male? A clinical relationship study of anthropometric features and 4-strand hamstring graft sizes. Malaysian Orthopaedic Journal 4:9-12. https://doi.org/10.5704/ MOJ.1007.001

21. Ho SWL, Tan TJL, Lee KT (2016) Role of anthropometric data in the prediction of 4-stranded hamstring graft size in anterior cruciate ligament reconstruction. Acta Orthop Belg 82:72-77

22. Mardani-Kivi M, Karimi-Mobarakeh M, Mirbolook A et al (2016) Predicting the hamstring tendon diameter using anthropometric parameters. Arch Bone Jt Surg 4:314-317

23. Asif N, Ranjan R, Ahmed S et al (2016) Prediction of quadruple hamstring graft diameter for anterior cruciate ligament reconstruction by anthropometric measurements. Indian J Orthop 50:49-54. https://doi.org/10.4103/0019-5413.173521

Publisher's note Springer Nature remains neutral with regard to jurisdictional claims in published maps and institutional affiliations. 